ENSAYO

\title{
DON QUIJOTE, CERVANTES, EL JUSTO MEDIO
}

\section{Francisco Rico}

En este ensayo se sostiene que el Quijote de Cervantes tiene un indisimulable regusto a Aristóteles. Con hechos y con dichos, por todas las bocas la obra predica y remacha que la "virtud ... está puesta entre dos extremos viciosos" (II, 17) y "el punto de la discreción" es "el medio" entre dos extremos (II, 51). La trama y los caracteres, los modos de contar, la ironía de los enfoques y las modestas lecciones del relato estriban a cada paso en la confrontación de unos extremos y en la propuesta más implícita de un justo

Francisco Rico. Catedrático de literaturas hispánicas medievales en la Universidad Autónoma de Barcelona y miembro de la Real Academia Española y de la British Academy. Editor de la edición de Don Quijote de la Mancha publicada el año 2004 por la Real Academia Española y la Asociación de Academias de la Lengua Española. Dirige para la editorial Crítica, de Barcelona, la colección "Biblioteca Clásica". Es asesor de las principales publicaciones europeas y norteamericanas de filología, y a él se deben asimismo abundantes estudios que han tenido especial influencia en la renovación de los métodos de la historiografía literaria y en el conocimiento de materias como las letras en la Edad Media, los orígenes de la literatura española, Petrarca y el humanismo europeo. Entre sus últimos libros se cuentan Texto y contextos. Estudios sobre la poesía española del siglo XV, Breve biblioteca de autores españoles (Seix Barral, 1990), Figuras con paisaje (Galaxia Gutenberg, 1994), La novela picaresca y el punto de vista (Seix Barral, 2000), El sueño del humanismo (Ediciones Destino, 2002, traducido al italiano, al francés y al japonés), Estudios de literatura y otras cosas (Ed. Destino, 2003), Los discursos del gusto: Notas sobre clásicos y contemporáneos (Ed. Destino, 2003), El pequeño mundo del hombre (Ed. Destino, 2005).

Estudios Públicos, 100 (primavera 2005). 
medio. Si el ciudadano Cervantes tendía a pensar en términos semejantes, advierte Francisco Rico, nadie lo sabrá nunca con certeza. No obstante — se señala al mismo tiempo - pocos autores son tan invisibles y a la vez tan presentes en un libro como Cervantes en el Quijote. Aun cuando Cervantes rehúye las referencias palmarias a sí mismo, e incluso escatima al narrador el empleo del yo, la sombra del escritor resulta ubicua en el tono que rezuma la novela entera.

$\mathrm{E}$ dato más seguro para explicar la excepcional fortuna del Quijote es la fascinación que produce la figura del protagonista (con la silueta del autor al trasluz). En la literatura de todos los tiempos, tal vez ningún otro personaje ha logrado conjugar tantos valores auténticos e ilusorios y, por ahí, suscitar tan perdurablemente la carcajada a la vez que la admiración. Raya en el milagro (y es el secreto de un arte y de un talante) que Cervantes lograra reunir en don Quijote facetas tan contrapuestas, contradictorias o a primera vista inconciliables, y conseguir un efecto de tan arrebatadora naturalidad. Pero ¿hay que recordar que cosa similar hallamos, a diversa escala, en los demás personajes, con Sancho, por supuesto, a la cabeza?

Entre quienes intervienen efectivamente en la acción, ninguno se deja colgar una única etiqueta: todos muestran varias caras, todos tienen sus razones, y con todos acaba por simpatizar el lector, que, en un balance final, a todos absolvería. Odioso como pocos aparece el capellán palaciego que condena destempladamente los desatinos de don Quijote y tacha al duque de no menor "mentecato" por espolearlo "para que lleve adelante sus sandeces y vaciedades". Cervantes mismo anuncia la presencia del "grave eclesiástico" en términos excepcionalmente hostiles. Y, no obstante, ¿quién duda de que el "venerable varón" está en su papel y en lo justo al denunciar la farsa que se traen los duques y exhortar a don Quijote a volver a casa, atender a sus quehaceres y no andar más "vagando por el mundo, papando aire y dando que reír - le espeta - a cuantos os conocen y no conocen" (II, 31). Las burlas de los nobles señores resultan más de una vez crueles o desconsideradas, sobre uniformemente caprichosas. Pero los duques ponen un exquisito interés en que don Quijote no se sienta herido ni por el menor detalle, antes bien le dan la mayor alegría de todas sus peripe- 
cias: "aquél fue el primer día que de todo en todo conoció y creyó ser caballero andante verdadero, y no fantástico, viéndose tratar del mismo modo que él había leído se trataban los tales caballeros en los pasados siglos" (II, 31). Incluso los personajes dibujados con unos colores llevan expresa o implícita una contrafigura de signo opuesto.

La dualidad o multiplicidad de modos de ser no está sólo en las actitudes y conductas de cada personaje, sino asimismo en la manera en que Cervantes confronta a unos con otros. En particular, la narración persevera en recoger las distintas perspectivas con que los participantes contemplan una misma escena, para que todas se maticen mutuamente y sean tomadas en cuenta por el lector. Típico el momento en que don Quijote se viene al suelo "muy mal parado" de un descomunal bastonazo, y Sancho se arroja "sobre el cuerpo de su señor haciendo sobre él el más doloroso y risueño llanto del mundo, creyendo que estaba muerto" (II, 52). Correctamente anota Rodríguez Marín: "doloroso para Sancho y risueño para los que lo presenciaban". Cervantes nos propone todas las posibilidades en juego.

Unos párrafos más arriba, don Quijote, ofendido por las palabras del cabrero, le da con un pan "en todo el rostro". El atacado replica "asiéndole del cuello con entrambas manos" y "no dudara de ahogalle, si Sancho Panza no llegara en aquel momento" a defenderlo, con la ayuda de otros espectadores, mientras "reventaban de risa el canónigo y el cura" y "saltaban los cuadrilleros" de contento (I, 52). El lance no se relata exclusivamente desde el punto de vista de estos últimos testigos: el novelista se pone también en la piel del cabrero, "lleno de sangre el rostro"; "del pobre caballero" que sangraba no menos; del escudero que "se desesperaba porque no se podía desasir de un criado del canónigo, que le estorbaba que a su amo no ayudase". Es locuaz la frase con que se da fin al lance: "En resolución, estando todos en regocijo y fiesta, sino los dos aporreantes que se carpían..." Cervantes hace más que no descuidar ninguna perspectiva: a la luz de esa nota de jolgorio, comprendemos que no llega al río tanta sangre como se nombra, que la sangre se halla menos en las caras que en la mente de los contendientes en pleno ardor de la pelea. Ni se nos escapa el guiño del escritor: de acuerdo con el tono de "regocijo y fiesta", la narración ha tendido a exagerar los palos, como el cine mudo los bofetones o el guiñol los porrazos. Al igual que en tantos otros pasajes, señaló magistralmente Edward C. Riley, "nos vemos obligados a leer a Cervantes al mismo tiempo en serio y no en serio". 
Son muchos los factores que confluyen para acoger en el relato los variados semblantes de los personajes y de la vida, desplegando inagotables opciones de lectura. Cervantes, así, comienza la novela en primera persona, pero a renglón seguido alega las discrepancias con que como cronista fidedigno tropieza en la tradición oral (“Quieren decir...”), "los autores que de este caso escriben" y los "anales de la Mancha". A no tardar, la historia de don Quijote se atribuye a un moro de opereta, Cide Hamete Benengeli, y Cervantes pasa a ser el "segundo autor", un modesto escoliasta. Pero sabido era que "de los moros no se podía esperar verdad alguna, porque todos son embelecadores, falsarios y quimeristas" (II, 3); y, encima, el bribón de Cide Hamete tenía el cuajo de no siempre referir las cosas "puntualmente", para que los lectores quedaran intrigados (II, 74). Nadie tomaría esas guasas a la letra. Si don Quijote imitaba a los caballeros de los libros, Cervantes imitaba jocosamente a sus presuntos autores. Como el juglar y el caricato, por otra parte, como todo buen contador de historias, sabía animarlas cambiando de voces y asumiendo mudables identidades. Pero las bromas con las fuentes de información y los narradores surtidos no son mera burla: comportan todavía otro modo de revelarle nuevas dimensiones a la trama y añadírselas a cosas y personas.

Incluso unas calas muy elementales confirman que el Quijote se deja ver como un gran juego de contraposiciones que se buscan unas a otras como si esperaran conciliarse entre sí: en la caracterización del héroe y en las valoraciones e impresiones que provoca, en la pintura y en la interrelación de los demás personajes, en la forma de contar, en las máscaras del narrador... Un hermoso estudio de Américo Castro explicó los datos afines a ésos en la clave de un cierto pensamiento renacentista: Cervantes concibe "el punto de vista de cada uno" como "observatorio y fábrica de la realidad", "prisma de la realidad, que se ofrece así con muy diversas facetas", como una última armonía de las discordancias. La interpretación clásica de don Américo encierra sin duda una no chica parte de verdad - acaso más intemporal que acotada en el Renacimiento-, pero no tiene por qué ser exclusiva ni descartar otros factores intelectuales y personales.

La crítica a la moda de hace unos años insistía en que los textos dan cuenta de sí mismos sin necesidad de referirlos a la biografía, la intención ni las circunstancias del escritor. Lo cierto es que una obra literaria no se diferencia radicalmente de los demás productos del lenguaje, ni, como ellos, puede descifrarse a derechas sin referirla a un sujeto que la enuncia. Y 
sucede que pocos autores son tan invisibles y a la vez están tan presentes en un libro como Cervantes en el Quijote. No aludo a las páginas que manifiestantemente reflejan la "alta ocasión" de Lepanto y la punzante del cautiverio en Argel. Con ser cruciales, esas vivencias quizá determinaron menos el Quijote que las horas muertas en Esquivias o los días gastados en ventas ruines y caminos a trasmano. Tampoco pienso en los contados lugares en que asoma la cabeza un "tal de Saavedra" (I, 40) o el cura evoca a un "grande amigo ... más versado en desdichas que en versos" (I, 6). De hecho, Cervantes no sólo rehúye las referencias palmarias a sí mismo, sino que incluso escatima al narrador el empleo del yo. No, donde la sombra del escritor resulta ubicua es en el tono que rezuma la novela entera, en el talante comprensivo e irónico, penetrante y bienhumorado, que lo empapa todo y que al lector no se le ocurre atribuir a ningún autor ficticio ni limitar a ningún personaje, sino que por fuerza identifica con la fisonomía del Miguel de Cervantes que no en balde firma el prólogo.

Podemos sospechar pero no concretar las raíces biográficas de ese tono y ese talante. No pasemos de un ejemplo. Recordaba al principio la celada "de cartones" que don Quijote destroza al primer espadazo y luego da por buena "sin querer hacer nueva experiencia de ella". No es postura distinta de la que en definitiva adopta el caballero en cuanto a la existencia de Dulcinea: "En eso hay mucho que decir. Dios sabe si hay Dulcinea o no en el mundo, o si es fantástica o no es fantástica; y éstas no son de las cosas cuya averiguación se ha de llevar hasta el cabo" (II, 32). Pero ese asumir unos datos o unas apariencias, mejores o peores, y no meterse en más indagaciones reaparece en el Quijote por todos sitios. No otra cosa hacen muchos personajes, empezando por Sancho, que "nunca se puso a averiguar si era ínsula, ciudad, villa o lugar la que gobernaba" (II, 53); o el narrador, que no decide si las labradoras venían "sobre tres pollinos o pollinas", porque, "como no va mucho en esto, no hay para qué detenernos en averiguarlo" (II, 10); o el amigo que aconseja a Cervantes insertar al final de su libro un "largo catálogo de autores", puesto que "no habrá quien se ponga a averiguar si los seguistes o no los seguistes, no yéndole nada en ello" (I, Pról.).

Todo invita a conjeturar que Cervantes procedió según esos mismos criterios en bastantes coyunturas bien atestiguadas, sean su matrimonio con Catalina de Salazar, las relaciones peligrosas de sus hermanas y de su hija, o más de un negocio de pinta confusa. En la actuación del escritor, a 
menudo creemos advertir una distancia desencantada que lo induce a aceptar las cosas como son, en parte por no crearse problemas, por ganas de llevarse bien, por cortesía, y en parte por desconfianza y por una cierta aprensión de averiguar qué hay en cada caso de blanco y de negro, bueno y malo. A uno le parece que más de una vez, sobre todo en sus últimos quince años, al enfrentarse con determinadas situaciones, Miguel se atenía a la respuesta de la cabeza encantada de Barcelona, cuando don Quijote le pregunta si "fue verdad o fue sueño lo que yo cuento que me pasó en la cueva de Montesinos": "hay mucho que decir: de todo tiene" (II, 62). Si el ciudadano Cervantes tendía a pensar en términos semejantes, nadie lo sabrá nunca con certeza. Pero es seguro que esa actitud y tantas otras que concuerdan con ella responden en el Quijote a un temple y una fisonomía personales, no son pura construcción literaria de ningún "autor implícito", ni son menos verdaderas, 'biográficas', que una firma en cualquier documento. Estoy convencido de que, para numerosos lectores que lo ignoran casi todo sobre Cervantes, uno de los grandes atractivos del Quijote es la percepción de esa velada omnipresencia del autor, junto a la curiosidad, la simpatía y hasta el cariño por el individuo de carne y hueso que se adivina detrás del retablo.

Libro riquísimo en la sugerencia de "alusiones simbólicas" (es cita de Ortega), sería inútil (e impropio) pedirle que formulara expresamente ideas de especial profundidad o trascendencia (y desde luego no las formula) ni que se alineara con ningún sistema filosófico. No obstante, la imagen de la vida y de los hombres que con tanta eficacia transmite el Quijote tiene un indisimulable regusto a Aristóteles.

El texto abunda en reminiscencias y aun citas literales del Estagirita, llegadas quién sabe de dónde, pero lo significativo es la visión que supone del universo social y moral. Sin ir más lejos, el precavido "hay mucho que decir: de todo tiene", a cuenta de Dulcinea o de la Cueva de Montesinos, postula una conducta que se hace cargo de la complejidad y versatilidad de las realidades humanas y se resiste a someterlas a principios generales. Porque "las cosas . . e están sujetas a continua mudanza" (I, 8) y en la ciudad de los hombres no caben "demostraciones matemáticas" (I, 33, y II, 19), sino atenerse a "experiencia, madre de las ciencias todas" (I, 21). Quitadas las enseñanzas inconmovibles de la religión, la verdad de la vida diaria es la verdad de la retórica, una verdad quizá provisional pero eficaz, activa, encaminada a poner en marcha sentimientos y acciones, que pondera las limita- 
ciones de la naturaleza, los datos concretos de cada situación, las condiciones de cada persona, las posibilidades de éxito de cada empresa. A esas consideraciones obedecen los comportamientos que narrador y personajes evalúan de común acuerdo como acertados; y las cualidades que todos respetan, las más celebradas en el don Quijote cuerdo o que deslindan la lucidez dentro de la locura, son la "prudencia", la "discreción", el "buen entendimiento", la "industria"...

Tales pautas conforman las acciones y los juicios contemplados favorablemente a lo largo del Quijote y son también ejes de la ética y la política de Aristóteles, centradas en el empirismo y el sentido común, la phrónesis, el saber práctico y factible, la convivialidad como meta. Claro está que se trata de nociones tan naturales y tan arraigadas, que no en todas partes pueden reconocerse como aristotélicas. La generalidad y la racionalidad de las ideas cristalizadas en el Quijote tienen que ver justamente con el asentimiento que siempre han suscitado en la inmensa mayoría de los lectores: en el balance final, la "filosofía del Quijote" es una llana sabiduría de la sensatez, la atención a las razones de los otros, la bonhomía, la cautela, la urbanidad..., que difícilmente disgustará a nadie. Pero si "todos los hombres — según dice Borges que dice Coleridge — nacen aristotélicos o platónicos", aunque ninguno sea lo uno ni lo otro a título exclusivo, Cervantes nació aristotélico y luego mamó el aristotelismo en las escuelas, en los libros y en el trato con los mejores ingenios.

La doctrina del justo medio es uno de los planteamientos que en otro marco se difuminarían como lugares comunes, pero cuya centralidad en el Quijote nos obliga a remontar a Aristóteles. Con hechos y con dichos, por todas las bocas, en ocasiones con matices que el Estagirita no habría reprobado (así los de don Quijote argumentando ante el Caballero del Verde Gabán), la obra predica y remacha que la "virtud . . . está puesta entre dos extremos viciosos" (II, 17) y "el punto de la discreción" es "el medio" entre "dos extremos" (II, 51). Ni el autor ni sus criaturas ignoran sin embargo la fascinación y la fuerza imperiosa de los extremos. Por el contrario, la trama y los caracteres, los modos de contar, la ironía de los enfoques y las modestas lecciones del relato estriban a cada paso en la confrontación de unos extremos y en la propuesta más o menos implícita de un justo medio. Don Quijote frente a sí mismo y en pareja con Sancho, las varias caras y razones de los personajes, las distintas perspectivas del narrador, la ambigua objetividad en la presentación de seres y aconteceres, el mismo problema medular 
de una ficción que oponga y a la postre case las "fábulas mentirosas" con "la verisimilitud y la imitación” (I, 47), ¿no son acaso otras tantas versiones del ideal del justo medio? 